Case Report

\title{
Intrathyroidal Parathyroid Carcinoma: Report of an Unusual Case and Review of the Literature
}

\author{
Lizette Vila Duckworth, ${ }^{1}$ William E. Winter, ${ }^{1}$ Mikhail Vaysberg, ${ }^{2}$ \\ César A. Moran, ${ }^{3}$ and Samer Z. Al-Quran ${ }^{1}$ \\ ${ }^{1}$ Department of Pathology, University of Florida College of Medicine, P.O. Box 100275, Gainesville, FL 32610-0275, USA \\ ${ }^{2}$ Department of Otolaryngology, University of Florida College of Medicine, Gainesville, FL 32610-0264, USA \\ ${ }^{3}$ Department of Pathology, MD Anderson Cancer Center, Houston, TX 77030, USA
}

Correspondence should be addressed to Lizette Vila Duckworth; lvila@ufl.edu

Received 17 May 2013; Accepted 12 June 2013

Academic Editors: K. Aozasa, T. Batinac, T. Hasebe, P. Perrini, M. M. Picken, P. Tosi, and T. Tot

Copyright (C) 2013 Lizette Vila Duckworth et al. This is an open access article distributed under the Creative Commons Attribution License, which permits unrestricted use, distribution, and reproduction in any medium, provided the original work is properly cited.

\begin{abstract}
Intrathyroidal parathyroid carcinoma is an exceedingly rare cause of primary hyperparathyroidism. A 51-year-old African American female presented with goiter, hyperparathyroidism, and symptomatic hypercalcemia. Sestamibi scan revealed diffuse activity within an enlarged thyroid gland with uptake in the right thyroid lobe suggestive of hyperfunctioning parathyroid tissue. The patient underwent thyroidectomy and parathyroidectomy. At exploration, a $2.0 \mathrm{~cm}$ nodule in the usual location of the right inferior parathyroid was sent for intraoperative frozen consultation, which revealed only ectopic thyroid tissue. No parathyroid glands were identified grossly on the external aspect of the thyroid. Interestingly, postoperative parathyroid hormone levels normalized after removal of the thyroid gland. Examination of the thyroidectomy specimen revealed a $1.4 \mathrm{~cm}$ parathyroid nodule located within the parenchyma of the right superior thyroid, with capsular and vascular invasion and local infiltration into surrounding thyroid tissue. We present only the eighth reported case of intrathyroidal parathyroid carcinoma and review the literature.
\end{abstract}

\section{Introduction}

Parathyroid carcinoma is a rare clinical entity comprising 0.5 to $2 \%$ of patients who present with primary hyperparathyroidism. Equally unusual is the presence of an intrathyroidal parathyroid gland $(0.2 \%)$, which originates from aberrant migration of the parathyroid gland(s) from the third and fourth branchial pouches [1]. We report an unusual case of parathyroid carcinoma arising from intrathyroidal parathyroid tissue and review the related literature.

\section{Case Report}

A 51-year-old African American female presented to our institution with thyromegaly and fatigue. Thyroid function tests were consistent with hypothyroidism. Thyroid ultrasound and radioactive uptake scan demonstrated diffuse goiter, with a dominant cold nodule $(4.0 \times 2.6 \times 2.5 \mathrm{~cm})$ in the inferior right thyroid lobe. The patient elected not to undergo biopsy and/or thyroidectomy at that time. A repeat radioactive uptake scan three years later again demonstrated diffuse goiter with a stable cold nodule in the right inferior thyroid lobe. Fine needle aspiration of this nodule was performed which yielded scant colloid and follicular cells in an occasional microfollicular pattern, indeterminate for a follicular neoplasm. Additionally, the patient was found to have elevated calcium levels in the range from 12.6 to $14.0 \mathrm{mg} / \mathrm{dL}$ (reference range $8.0-10.6 \mathrm{mg} / \mathrm{dL}$ ), low phosphorous levels from 2.4 to $2.6 \mathrm{mg} / \mathrm{dL}$ ( $2.7-4.5 \mathrm{mg} / \mathrm{dL})$, and markedly elevated intact parathyroid hormone (PTH) ranging from 303 to $579 \mathrm{pg} / \mathrm{mL}(15-65 \mathrm{pg} / \mathrm{mL})$. In retrospect, the patient had elevated calcium levels for several years and had symptoms relating to hypercalcemia including fatigue, bone pain, abdominal pain, and memory loss. Vitamin D levels showed a low 25-hydroxyvitamin $\mathrm{D}$ of $7 \mathrm{ng} / \mathrm{dL}(10-50 \mathrm{ng} / \mathrm{mL})$ and high 1,25 dihydroxyvitamin $\mathrm{D}$ of $103 \mathrm{pg} / \mathrm{mL}(15-60 \mathrm{pg} / \mathrm{mL})$, consistent with primary hyperparathyroidism. Sestamibi scan revealed diffuse activity within an enlarged thyroid gland 


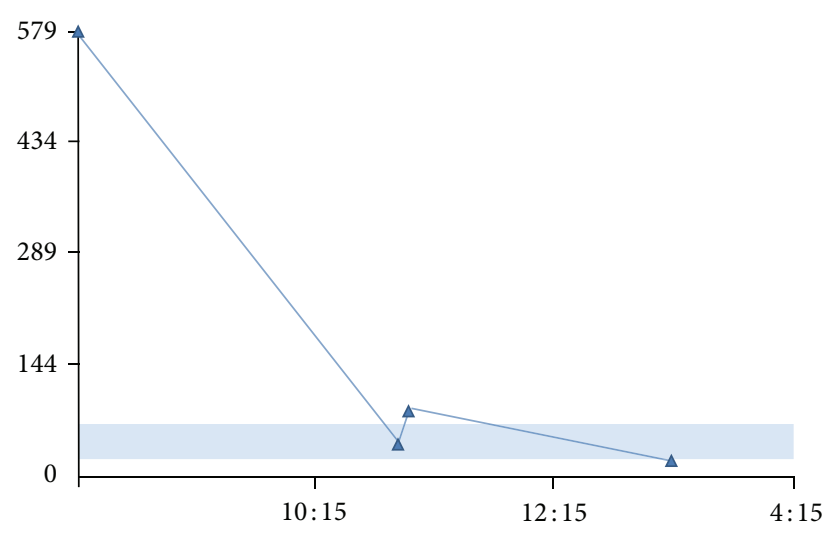

$\Delta$ PTH intact $(\mathrm{pg} / \mathrm{mL})$

FIGURE 1: Intraoperative monitoring of PTH levels. Graph depicts marked decrease in parathyroid hormone levels following thyroidectomy. PTH hormone dropped initially from 579 to $40 \mathrm{pg} / \mathrm{mL}$, then $83 \mathrm{pg} / \mathrm{mL}$, and finally to $16 \mathrm{pg} / \mathrm{mL}$. (PTH level is on $y$-axis, time is on $x$-axis, and shaded box represents PTH reference range from 15 to $65 \mathrm{pg} / \mathrm{mL}$.)

with uptake in the right lobe suggestive of hyperfunctioning parathyroid tissue. Although imaging was not entirely classic for a parathyroid adenoma, this could not be excluded. The patient elected to proceed with thyroidectomy and parathyroidectomy due to compressive symptoms from her goiter and symptomatic hypercalcemia. During neck exploration, a $2.0 \mathrm{~cm}$ nodule in the usual location of the right inferior parathyroid, thought to be an adenoma, was removed and sent for intraoperative frozen consultation. Frozen section examination revealed only ectopic thyroid tissue with no parathyroid tissue identified. No additional parathyroid tissue was identified grossly on the external aspect of the thyroid. Interestingly, following removal of the entire thyroid gland, intraoperative PTH levels decreased to 40 , then 83 , and finally to $16 \mathrm{pg} / \mathrm{mL}$ ten minutes postoperatively (see Figure 1).

Gross examination of the thyroid revealed a diffusely enlarged gland (95.5 g), distorted by multiple soft, redtan nodules varying from 0.4 to $4.5 \mathrm{~cm}$ in size, with a dominant nodule in the right inferior thyroid which had been previously needled. Histologically, these nodules were consistent with adenomatoid nodules (nodular goiter) with focal nonspecific lymphocytic thyroiditis. Cut surface of the thyroid gland revealed an additional $1.4 \times 1.4 \times 0.9 \mathrm{~cm}$ soft, yellow-tan nodule located within the parenchyma of the right superior thyroid. Microscopic examination of this nodule revealed cellular nests of clear to eosinophilic epithelioid cells divided by dense bands of fibrosis and surrounded by a thick fibrous capsule (Figure 2). Areas of invasion through the capsule into surrounding normal thyroid tissue, as well as areas of vascular invasion, were identified at the periphery of the tumor. Focally, the tumor cells had a perivascular arrangement with basally located nuclei. The tumor cells contained hyperchromatic to vesicular nuclei with prominent macronucleoli and occasional intranuclear inclusions.
Mitotic count was 3 per 50 high-power fields. Immunohistochemical studies revealed that tumor cells were strongly immunoreactive for PTH and negative for calcitonin, TTF1 , and thyroglobulin, thus confirming that the tumor cells were parathyroid in origin. The tumor cells were also positive for renal cell carcinoma marker (RCC), but negative for CD10, S-100, synaptophysin, chromogranin, and Hep-Par-1. Ki-67 demonstrated a proliferation index of approximately $5 \%$ in tumor cells. Two-level VI lymph nodes submitted for evaluation were negative for metastatic carcinoma. Based on the findings of capsular and vascular invasions and local infiltration into the thyroid gland, a diagnosis of parathyroid carcinoma was made. The patient was managed with surgery alone, without adjuvant radiation, and continues to do well with no evidence of recurrent disease after 2.5 years of followup.

\section{Discussion}

Parathyroid carcinoma is an exceedingly rare clinical entity, which occurs equally in males and females with a median age of 45 years. Parathyroid carcinoma often presents as a mass that is adherent to adjacent structures. Laboratory criteria to distinguish parathyroid adenoma from carcinoma are nonspecific. The clinical criteria of local invasion and/or metastases are usually required for the diagnosis of parathyroid carcinoma, as histologic features alone cannot entirely distinguish between an adenoma and carcinoma. Capsular, vascular, and perineural invasions are usually reliable indicators of malignancy. Other histologic features more commonly seen in carcinoma include a trabecular growth pattern with dense fibrous bands, tumor cell necrosis, tumor cell monotony, increased nuclear to cytoplasmic ratio, spindling of tumor cells, prominent irregular macronucleoli, and increased or atypical mitotic figures. In addition, higher expression of Ki-67, lower expression of p27kip1, and cyclin D1 overexpression have been demonstrated in carcinomas versus adenoma/hyperplasia [2-4]. Loss of nuclear parafibromin, a protein encoded by the putative tumor suppressor gene HRPT2, has also been shown to be a highly sensitive and specific marker for the diagnosis of parathyroid carcinoma [5].

Approximately 700 cases of parathyroid carcinoma have been reported to date, and, to the best of our knowledge, only seven cases of intrathyroidal parathyroid carcinoma have been previously documented (see Table 1) [6-13]. Ernst et al. reported the first case of intrathyroidal parathyroid carcinoma in a patient presenting with hyperparathyroidism [6]. Crescenzo et al. later presented a case of intrathyroidal parathyroid carcinoma in a patient who presented with a left neck mass [7]. Other presentations of intrathyroidal parathyroid carcinoma have included goiter and symptoms relating to hypercalcemia [9-13]. Herrera-Hernández et al. described the first case of intrathyroidal parathyroid carcinoma occurring in a pediatric patient [12]. Sestamibi scan was helpful in three cases in localizing the parathyroid gland 


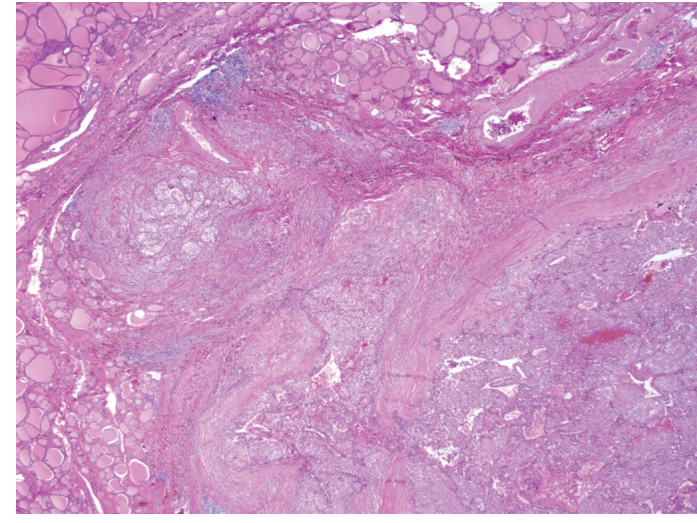

(a)

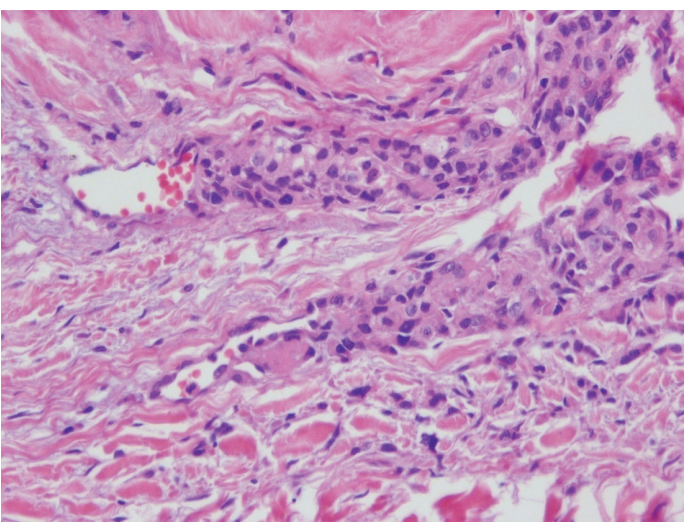

(c)

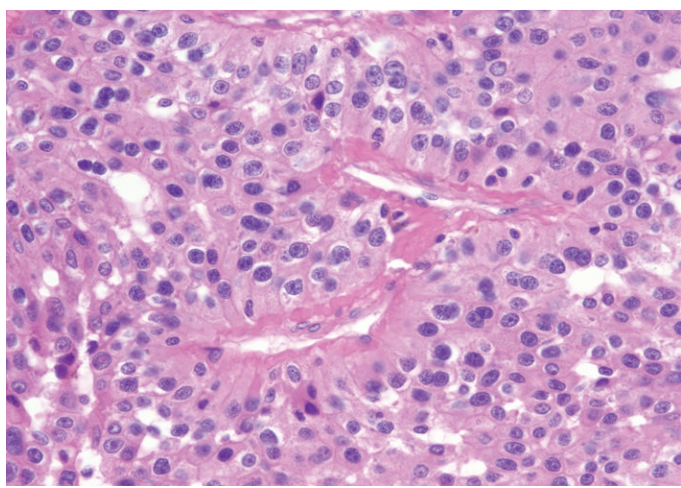

(e)

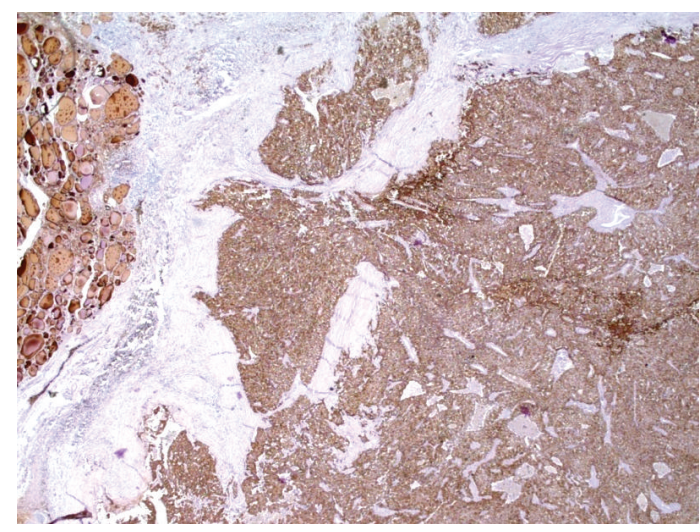

(b)

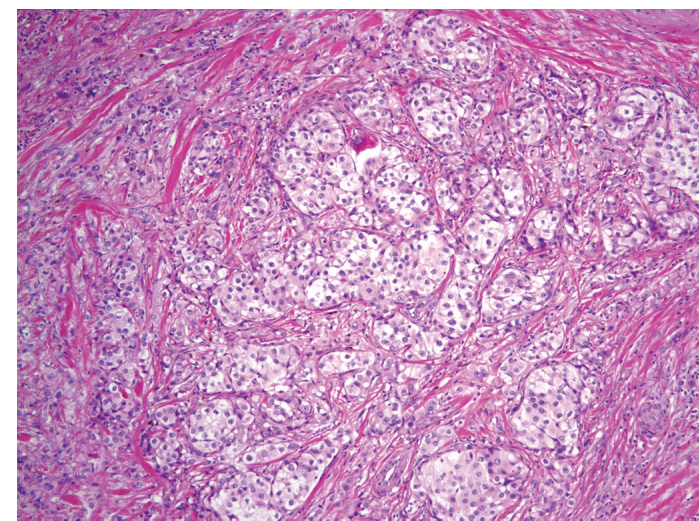

(d)

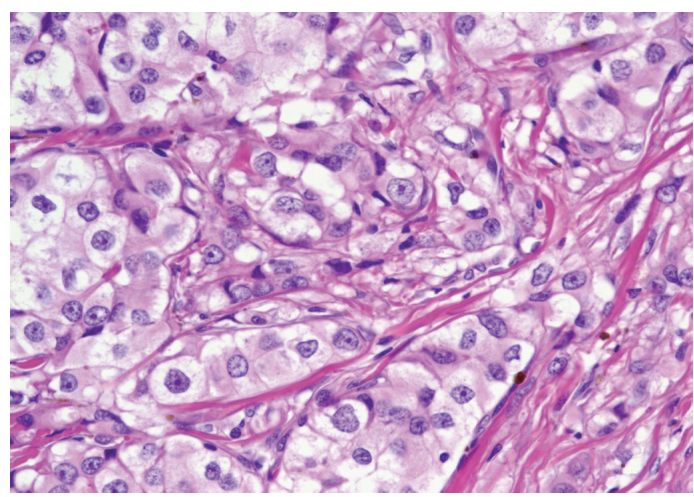

(f)

FIGURE 2: Microscopic appearance of intrathyroidal parathyroid carcinoma. (a) Extracapsular extension ("mushroom projection") of neoplastic cells through the capsule into surrounding thyroid parenchyma (hematoxylin and eosin stain (H\&E); magnification 20x). (b) Immunohistochemistry for parathyroid hormone (PTH) shows strong and diffuse immunoreactivity in tumor cells and highlights areas of capsular invasion. There is nonspecific staining of colloid in thyroid follicles in the upper left (20x). (c) Foci of vascular invasion seen at the periphery of the tumor (H\&E; 100x). (d) Trabecular arrangement of tumor cells traversed by thick bands of collagen (H\&E; 40x). (e) Focal perivascular arrangement of tumor cells around vessels (H\&E; 200x). (f) Cytologic features of tumor cells demonstrating tumor cell monotony with clear to eosinophilic cytoplasm and prominent macronucleoli (H\&E; 400x).

before surgical exploration $[8,10,12]$. Findings of lymphocytic thyroiditis, similar to our case, and a microscopic focus of papillary thyroid carcinoma were detected in a case by Schmidt et al. [9]. Ordoñez et al. described a rare case of intrathyroidal parathyroid tumor producing amyloid, mimicking medullary carcinoma of the thyroid gland [14].
Nonfunctioning intrathyroidal parathyroid carcinomas have not been described.

Recognition of this rare entity is important as parathyroid carcinoma has a high probability of local recurrence and the potential to metastasize to regional nodes and distant sites late in its course. Reported five-year survival rates range from 
TABLE 1: Literature review of published intrathyroidal parathyroid carcinoma cases.

\begin{tabular}{|c|c|c|c|c|c|c|}
\hline Reference & Case no. & Age/sex & Presentation & $\begin{array}{l}\text { Tumor location } \\
\text { and size }\end{array}$ & Treatment & Outcome \\
\hline Ernst et al., 1993 [6] & 1 & $52 / \mathrm{F}$ & Hyperparathyroidism/hypercalcemia & $\begin{array}{l}\text { Left thyroid, } \\
2.5 \mathrm{~cm}\end{array}$ & Left thyroidectomy & $\mathrm{NED}, 4 \mathrm{mo}$ \\
\hline Crescenzo et al., 1998 [7] & 2 & $60 / \mathrm{F}$ & $\begin{array}{l}\text { Left neck mass, hyperparathyroidism/ } \\
\text { hypercalcemia }\end{array}$ & $\begin{array}{l}\text { Left thyroid, } \\
1.5 \mathrm{~cm}\end{array}$ & $\begin{array}{l}\text { Left thyroidectomy, } \\
\text { isthmusectomy }\end{array}$ & $\mathrm{NED}, 18 \mathrm{mo}$ \\
\hline $\begin{array}{l}\text { Kirstein and Ghosh, } \\
2001[8]\end{array}$ & 3 & $74 / \mathrm{M}$ & Hyperparathyroidism & $\begin{array}{l}\text { Left thyroid, } \\
\text { NR }\end{array}$ & Left thyroidectomy & NR \\
\hline Schmidt et al., 2002 [9] & 4 & $76 / \mathrm{F}$ & Hyperparathyroidism/hypercalcemia & $\begin{array}{l}\text { Right superior } \\
\text { thyroid, } 3.2 \mathrm{~cm}\end{array}$ & $\begin{array}{l}\text { Right thyroidectomy, } \\
\text { isthmusectomy }\end{array}$ & $\mathrm{NED}, 1 \mathrm{yr}$ \\
\hline Hussein et al., 2006 [10] & $5^{*}$ & $63 / \mathrm{F}$ & Hyperparathyroidism/hypercalcemia & $\begin{array}{l}\text { Left thyroid, } \\
\quad 6.0 \mathrm{~cm}\end{array}$ & Left thyroidectomy & $\mathrm{NED},>1 \mathrm{mo}$ \\
\hline Foppiani et al., 2007 [11] & 6 & $67 / \mathrm{F}$ & $\begin{array}{l}\text { Hyperparathyroidism/hypercalcemia, } \\
\text { multinodular goiter }\end{array}$ & $\begin{array}{l}\text { Right inferior } \\
\text { thyroid, } 3.0 \mathrm{~cm}\end{array}$ & Total thyroidectomy & NED, 5 yr \\
\hline $\begin{array}{l}\text { Herrera-Hernández et } \\
\text { al., } 2011 \text { [12] }\end{array}$ & 7 & $14 / \mathrm{F}$ & Hyperparathyroidism/hypercalcemia & $\begin{array}{l}\text { Right thyroid, } \\
2.5 \mathrm{~cm}\end{array}$ & Right thyroidectomy & $\mathrm{NED}, 18 \mathrm{mo}$ \\
\hline $\begin{array}{l}\text { Vila Duckworth et al., } \\
\text { present case }\end{array}$ & 8 & $51 / \mathrm{F}$ & $\begin{array}{c}\text { Hyperparathyroidism/hypercalcemia, } \\
\text { thyromegaly }\end{array}$ & $\begin{array}{l}\text { Right superior } \\
\text { thyroid, } 1.4 \mathrm{~cm}\end{array}$ & Total thyroidectomy & $\mathrm{NED}, 2.5 \mathrm{yr}$ \\
\hline
\end{tabular}

NR indicates not reported; NED: no evidence of disease; mo: months; yr: years.

${ }^{*}$ Case apparently also described by Temmim et al. 2008 [13].

50 to $85.5 \%$. The presence of macronucleoli, greater than 5 mitoses per 50 high-power fields, and necrosis are regarded by some to be poor prognostic factors associated with recurrent disease [15]. Complete surgical excision is the primary treatment with or without postoperative radiation. Important to exclude in the differential diagnosis are intrathyroidal parathyroid adenoma, follicular thyroid carcinoma (TTF-1 and thyroglobulin positive, PTH negative), and medullary thyroid carcinoma (TTF-1 and calcitonin positive, thyroglobulin and PTH negative). In addition, expression of RCC should not be mistaken for metastatic renal cell carcinoma, as RCC positivity has been demonstrated in several nonrenal tumors, including parathyroid carcinomas [16].

\section{Abbreviations}

PTH: Parathyroid hormone.

\section{References}

[1] H. R. Harach and G. M. Vujanic, "Intrathyroidal parathyroid," Pediatric Pathology, vol. 13, no. 1, pp. 71-74, 1993.

[2] M. P. Vargas, H. I. Vargas, D. E. Kleiner, and M. J. Merino, "The role of prognostic markers (MiB-1, RB and bcl-2) in the diagnosis of parathyroid tumors," Modern Pathology, vol. 10, no. 1, pp. 12-17, 1997.

[3] M. A. Vasef, R. K. Brynes, M. Sturm, C. Bromley, and R. A. Robinson, "Expression of cyclin D1 in parathyroid carcinomas, adenomas, and hyperplasias: a paraffin immunohistochemical study," Modern Pathology, vol. 12, no. 4, pp. 412-416, 1999.

[4] L. A. Erickson, L. Jin, P. Wollan, G. B. Thompson, J. A. van Heerden, and R. V. Lloyd, "Parathyroid hyperplasia, adenomas, and carcinomas: differential expression of p27(Kip1) protein," American Journal of Surgical Pathology, vol. 23, no. 3, pp. 288$295,1999$.
[5] M. Tan, C. Morrison, P. Wang et al., "Loss of parafibromin immunoreactivity is a distinguishing feature of parathyroid carcinoma," Clinical Cancer Research, vol. 10, no. 19, pp. 66296637, 2004.

[6] M. Ernst, M. Lippmann, and B. Fleige, "Primary hyperparathyroidism due to parathyroid cancer in the left thyroid lobe," Zentralblatt fur Chirurgie, vol. 118, no. 11, pp. 682-686, 1993.

[7] D. G. Crescenzo, M. Shabahang, D. Garvin, and S. R. T. Evans, "Intrathyroidal parathyroid cancer presenting as a left neck mass," Thyroid, vol. 8, no. 7, pp. 597-599, 1998.

[8] L. J. Kirstein and B. C. Ghosh, "Intrathyroid parathyroid carcinoma," Journal of Surgical Oncology, vol. 77, no. 2, pp. 136$138,2001$.

[9] J. L. Schmidt, R. C. Perry, L. P. Philippsen, and H. H. Wu, "Intrathyroidal parathyroid carcinoma presenting with only hypercalcemia," Otolaryngology, vol. 127, no. 4, pp. 352-353, 2002.

[10] W. I. Hussein, T. A. El-Maghraby, and O. Al-Sanea, "Hyperfunctioning intrathyroidal parathyroid carcinoma," Saudi Medical Journal, vol. 27, no. 8, pp. 1226-1229, 2006.

[11] L. Foppiani, P. Del Monte, G. Sartini et al., "Intrathyroidal parathyroid carcinoma as cause of hypercalcemia and pitfall of localization techniques: clinical and biologic features," Endocrine Practice, vol. 13, no. 2, pp. 176-181, 2007.

[12] A. A. Herrera-Hernández, P. Aranda-Valderrama, J. A. DíazPérez, and L. P. Herrera, "Intrathyroidal parathyroid carcinoma in a pediatric patient," Pediatric Surgery International, vol. 27, no. 12, pp. 1361-1365, 2011.

[13] L. Temmim, F. Sinowatz, W. I. Hussein, O. Al-Sanea, and H. ElKhodary, "Intrathyroidal parathyroid carcinoma: a case report with clinical and histological findings," Diagnostic Pathology, vol. 3, no. 1, article 46, 2008.

[14] N. G. Ordoñez, M. L. Ibanez, N. A. Samaan, and R. C. Hickey, "Immunoperoxidase study of uncommon parathyroid tumors. Report of two cases of nonfunctioning parathyroid carcinoma and one intrathyroid parathyroid tumor-producing amyloid," 
American Journal of Surgical Pathology, vol. 7, no. 6, pp. 535$542,1983$.

[15] L. Bondeson, K. Sandelin, and L. Grimelius, "Histopathological variables and DNA cytometry in parathyroid carcinoma," American Journal of Surgical Pathology, vol. 17, no. 8, pp. 820-829, 1993.

[16] N. Bakshi, L. P. Kunju, T. Giordano, and R. B. Shah, "Expression of renal cell carcinoma antigen (RCC) in renal epithelial and nonrenal tumors: diagnostic implications," Applied Immunohistochemistry and Molecular Morphology, vol. 15, no. 3, pp. 310315, 2007. 


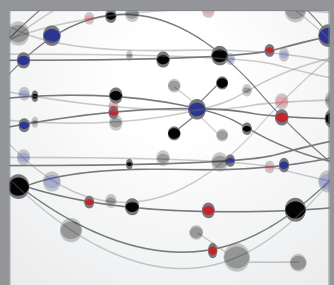

The Scientific World Journal
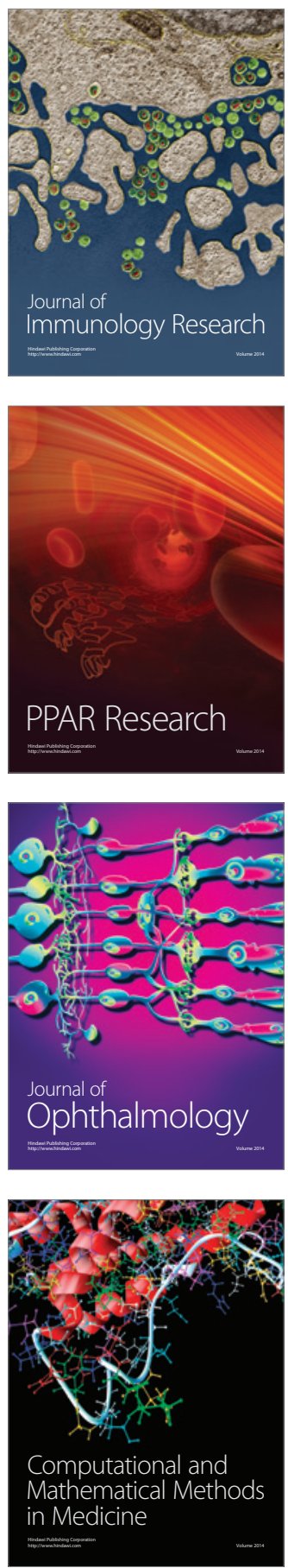

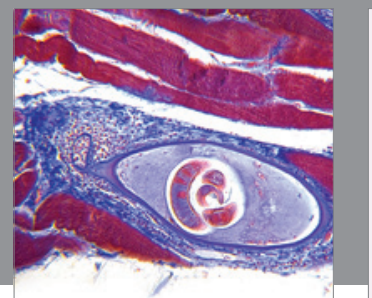

Gastroenterology

Research and Practice
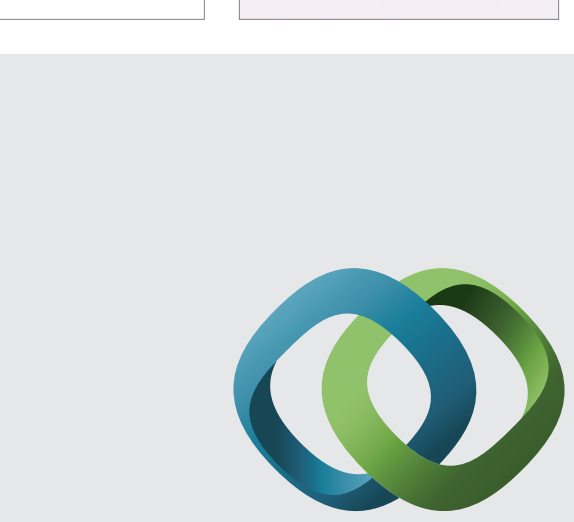

\section{Hindawi}

Submit your manuscripts at

http://www.hindawi.com
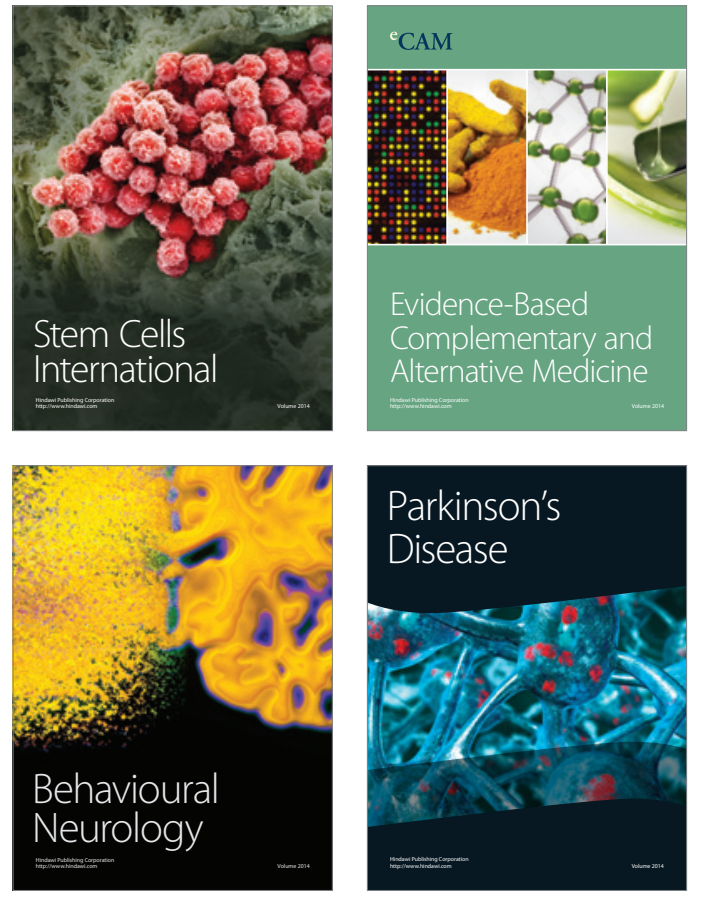
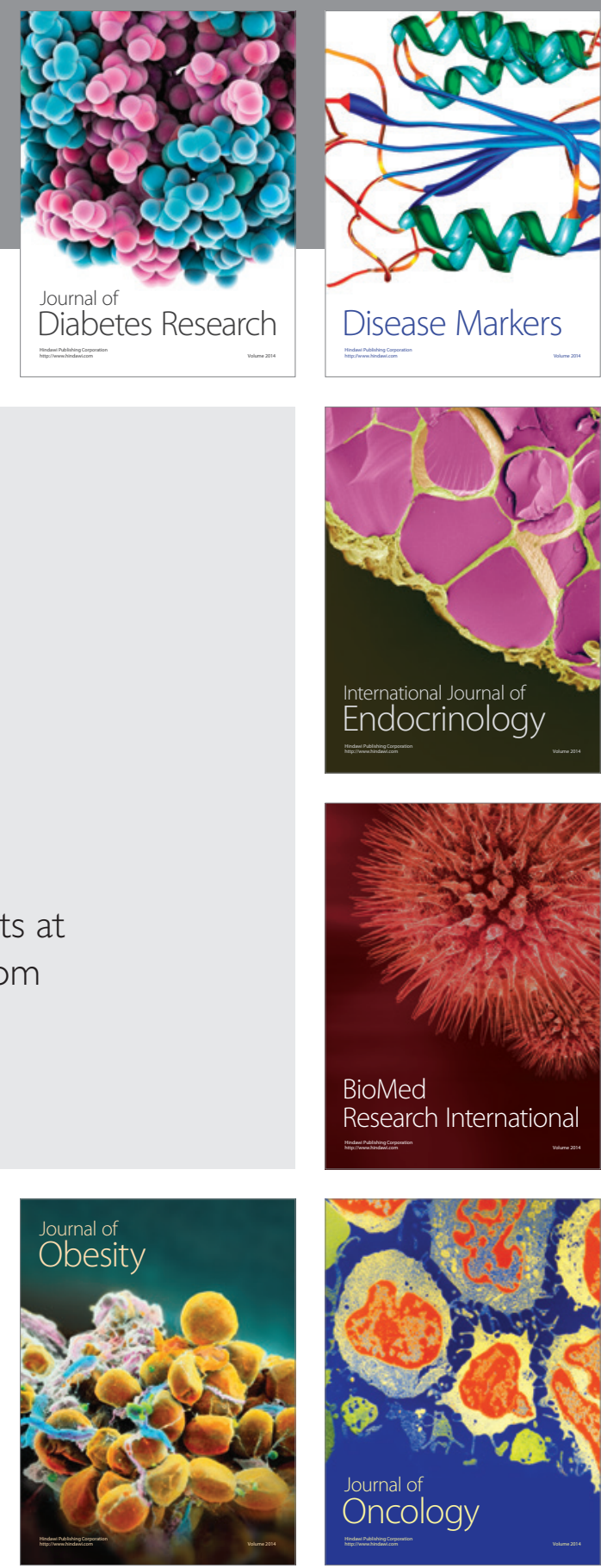

Disease Markers
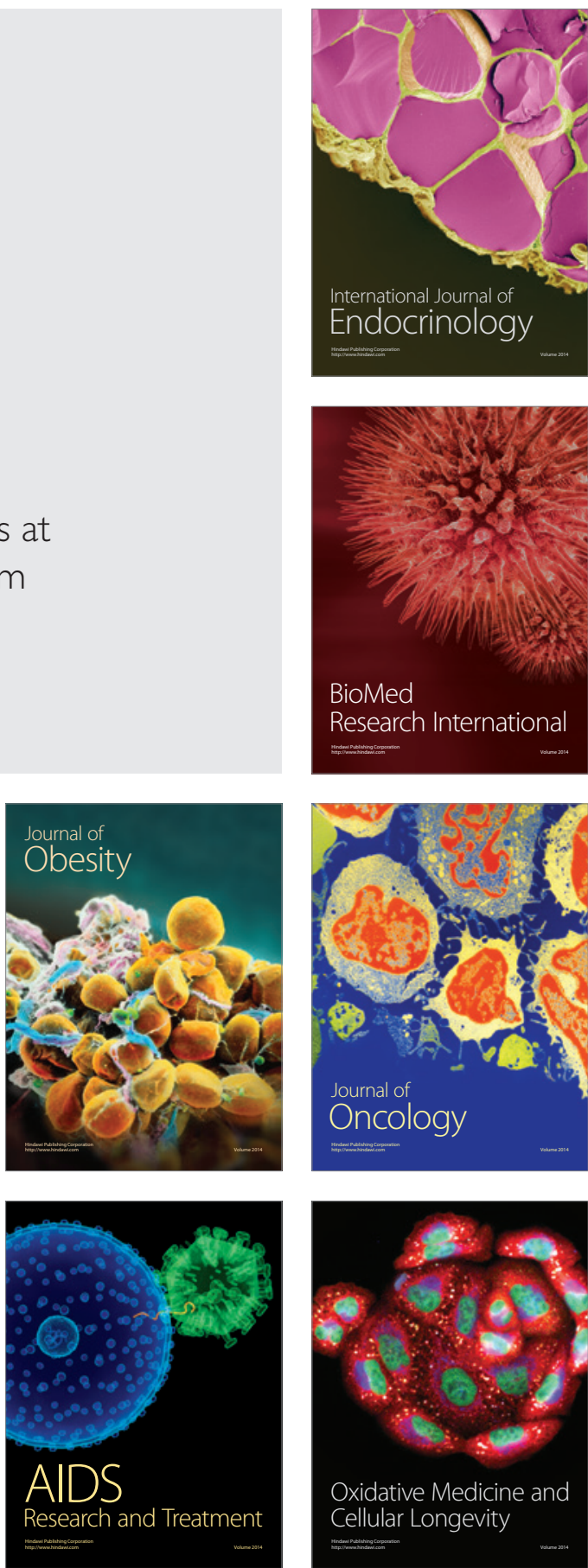